\title{
Depth profiling of degradation of multilayer photovoltaic backsheetsafter accelerated laboratory weathering: Cross-sectional Raman imaging
}

Chiao-Chi Lin,Peter J. Krommenhoek, Stephanie S. Watson, Xiaohong Gu*

Polymeric Materials Group, Engineering Laboratory,

National Institute of Standards and Technology (NIST),

Gaithersburg, MD 20899, USA

E-mail address: cclin@ nist.gov (C.-C. Lin)

peter.krommenhoek@nist.gov (P.J. Krommenhoek)

stephanie.watson@nist.gov (S.S. Watson)

xiaohong.gu@nist.gov (X.Gu)

* Corresponding author. +1 301975 6523; fax: +1 3019906891 .

Email Address:xiaohong.gu@nist.gov (X.Gu). 


\begin{abstract}
Understanding of thedurability of each individual layer and their interfaces in a multilayered photovoltaic (PV)backsheetis critical to the design and selection of materials for making reliable andhigh performance PV modules. In this study, Raman imaging was used to depth profile the chemical degradation of a multilayer commercial backsheetfilm exposed to ultra-violet (UV) radiationat $85^{\circ} \mathrm{C}, 5 \%$ relative humidity ( $\mathrm{RH}$, dry) and $85^{\circ} \mathrm{C}, 60 \%$ RH (humid)on the NIST (National Institute of Standards and Technology) SPHERE(Simulated Photodegradation via High Energy Radiant Exposure).The backsheetfilm wasa multipartlaminate comprising of a pigmented polyethylene terephthalate (PET)-based outer layer, PET core layer and three ethylene vinyl acetate (EVA) layers having different vinyl acetate(VA) contents, along with two inner adhesive layers between PET outer and PET core layers, and PET core and EVA layers. Cross-sectional samples were prepared by cryo-microtomyfor various characterizations.The multilayer structureswere examined by laser scanning confocal andatomic force microscopies, while their chemical degradation profiles were obtained by Raman spectroscopic imaging. Non-uniform degradation was observed in the agedbacksheet film, and both UV and moisture appeared tosignificantly affect the degradation profiles of the multilayers.Severe degradation, indicated by high fluorescence,occurredin the outermost region of the pigmented PET outer layer, and the degradation gradient extended to approximately $20 \mu \mathrm{m}$ to the bulk. It was also found thattheinner adhesive layerswere severelydeterioratedunder moist condition, indicating thatthe long-termadhesion between the layers could be a major area of concern for multilayer backsheets used in a humid environment. The relationship between the sharp
\end{abstract}


(non-uniform) degradation profile, resultant internal stress, and ultimate failures (cracking and delamination)was discussed as well.

Keywords:multilayeredbacksheet,photovoltaic module, cross-section, degradation profile, Raman imaging,accelerated laboratory weathering 


\section{Introduction}

Polymeric packaging materials are important to the safety, performance, durability, and reliability of photovoltaic (PV) modulesduring field operation. The backsheet, the outermost packaging material on the back side of a PV module that directly adheres to encapsulant, is the first line of back side defense against environmental aging in the field $[1,2]$. In general, the backsheet is a polymeric multilayer laminate system engineered so that each layer can address multiple purposes such as weatherability, insulation, adhesion promotion, and light reflection. Fluoropolymers are commonly used as the outermost weathering resistant layer of backsheets due to their chemical and thermal stability. Polyethylene terephthalate (PET) is often used as an insulation layer (usually core layer of the backsheet) because of its low cost, low electrical conductivity and high mechanical strength [1-3]. Moreover, to block ultra-violet (UV) from the back side and redirect reflected sunlight from the front side of a PV module, white inorganic pigments, such as titanium dioxide $\left(\mathrm{TiO}_{2}\right)$ and barium sulfate $\left(\mathrm{BaSO}_{4}\right)$, are widely used in backsheet layers to modify opacity and reflectivity of polymeric layers [2].

To improvelong-term stability and prolong service life of backsheets, complex additives such as antioxidants, hydrolysis stabilizers, heat stabilizers, UV absorbers/stabilizers, silane coupling agents, curing agents, and flame retardants are commonly added in the polymeric matrix of each layer for various purposes. The existence of additives results in the polymer degradation processes having multiple variable mechanisms. Usually, the amounts of each additive are as small as $0.1 \%$ to $2.0 \%$ mass fraction [4-8].Consequently, it is difficult to detect the additives using conventional vibrational spectroscopy.However, the formation of conjugated double bonds such as $\alpha, \beta$-unsaturated carbonyl groups during weathering may contribute significantly to the 
enhanced fluorescence and/or luminescence emissionwhendegraded samples are illuminated with UV or visible light [4]. Therefore, besides conventional vibrational spectroscopies,fluorescence and luminescence-based analytical techniques can be employed as a synergistic approach to monitor the extent of degradation [9-11].

The current requirement of greater than 25-year service life for PV module is a bigchallenge to module and backsheet manufacturers. Practical in-field testing results showed that significant backsheet failures such as cracking, yellowing and delamination occurred withina 5-year service [2].Previous research efforts have investigated backsheet degradation and failure by studying either individual material components or mini-modules $[2,3,12-18]$. Some studies focused on characterization of backsheet film as a whole as well asits top/bottom surfaces [2,14-16], while others addressed the adhesion behaviorsbetween layers by peeling tests $[3,12,13]$. However, there arelimited data showing a degradation profile acrossbacksheetlayers and how different aging stresses impact individual layers [17,18].For this reason, an in-depth investigation on the degradation profileof polymeric multilayer backsheetisneeded for a betterunderstanding of backsheet failure mechanisms.

Cross-sectional analysis can provide robust information for depth profiling of multilayer systems $[19,20]$. Raman spectroscopy is known to be non-destructive for samples, and can revealpolymer degradation by means of not only the fingerprint of vibrational spectrum but also fluorescence emission [10]. Furthermore, instead of single-point or one-dimensional spectroscopic characterization, two-dimensional spatialspectroscopy such as Raman imaginghas beenshownto accurately describecomplex polymeric components [21,22].For these reasons, we have employed the combination of cryo-microtomycross-sectioning and microscopic 
imagingtoinvestigatedegradation profile in multilayerbacksheet system.

In this study, a commercially availablebacksheet consisting of PET/PET/ethylene vinyl acetate (EVA), commonly named as PPE,was selected as a model sample due to its low costcompared to fluoropolymer-based backsheets. Unless stated otherwise, the accelerated laboratory weathering of multilayer PPE backsheetwas performed for 1600 hours (h)at $85{ }^{\circ} \mathrm{C} / 5 \% \mathrm{RH}$ (dry) and $85{ }^{\circ} \mathrm{C} / 60 \% \mathrm{RH}$ (humid)conditions on the NIST (National Institute of Standards and Technology)SPHERE(Simulated Photodegradation via High Energy Radiant Exposure) weathering chamber. The accumulated UV irradiance on each specimen is approximately $170 \mathrm{~W} / \mathrm{m}^{2}$ between $300 \mathrm{~nm}$ and $400 \mathrm{~nm}$ after $1600 \mathrm{~h}$ exposure on the SPHERE.Assuming $10 \%$ albedofor the reflected light on the backsheetduring field exposure [2,23], the UV dose for the $1600 \mathrm{~h}$ exposure $\left(\sim 980 \mathrm{MJ} / \mathrm{m}^{2}\right.$ between $300 \mathrm{~nm}$ and $\left.400 \mathrm{~nm}\right)$ is approximately equivalent to that of a 25-yearfield exposure on the back side of anon-rack PV module in Phoenix, Arizona.

To analyze the depth profile after degradation, cryo-microtomy was used to obtain cross-sectional PPE specimens with a flat surface parallel tothe film thickness. The evolution of the multilayer structure and chemical degradation profiles were examined before and after accelerated laboratory weathering by laser scanning confocal microscopy (LSCM),atomic force microscopy (AFM), and Raman imaging.

\section{Experimental*}

\subsection{Backsheet specimens and accelerated laboratory weathering}

A commercial, free-standing, multilayer PPE backsheet film was usedas received for

\footnotetext{
${ }^{*}$ Certain commercial equipment, instruments or materials are identified in this paper in order to specify the experimental procedure adequately. Such identification is not intended to imply recommendation or endorsement by the National Institute of Standards and Technology, nor is it intended to imply that the materials or equipment identified are necessarily the best available for this purpose.
} 
this study. Circular specimens with $19 \mathrm{~mm}$ in diameter were punched from the PPE backsheet film and then placed on a sample holder for accelerated laboratory weathering on the NIST 2-meter diameter integrating sphere-based high intensity UV weathering facility, referred to as SPHERE [24] at $85^{\circ} \mathrm{C} \pm 0.5{ }^{\circ} \mathrm{Cunder} 5 \% \pm 3 \% \mathrm{RH}$ (dry) and60 \% \pm 3 $\%$ RH (humid) for $1600 \mathrm{~h}$. A few specimens were exposed up to3280 h to investigate ultimate failure modes including cracking or delamination. The UV irradiance on the PET outer layer side of the samples was approximately $170 \mathrm{~W} / \mathrm{m}^{2}$ between $300 \mathrm{~nm}$ and 400 nm.

To prepare cross-sectional specimens, $3 \mathrm{~mm} \times 4 \mathrm{~mm}$ pieces cut from the center of the $19 \mathrm{~mm}$ circular sample were embedded in an epoxy molding. Cryo-microtoming was carried out on a Leica EM FC7 (Leica Mikrosysteme GmbH) with glass blade for coarse surfacing and then followed with diamond blade for fine surfacing. The liquid $\mathrm{N}_{2}$ was used to cool the sample, ensuring a brittle fracture resulted from the microtoming to minimize the surface roughness for microscopic and spectroscopic imaging [25]. The cross-section is parallel to the film thickness. Care was taken to make sure that the microtoming direction did not cross the layers of PPE to avoid smearing between layers as the blue arrow shown in Figure 1.

\subsection{Laser scanning confocal microscopy and atomic force microscopy characterizations}

Images of the cross-section and exposed(weathered) surfaces wereacquired using a Zeiss LSM510 META (Carl Zeiss, Inc., Oberkochen, Germany) laser scanning confocal microscope in reflection mode with a laser wavelength of $543 \mathrm{~nm}$. A series of single images (optical slices) each having a z-direction step size of $100 \mathrm{~nm}$ were obtained by adjusting the focal plane in the z-direction. Objectives of 10xand 50x(Zeiss, Germany) 
were used to observe two or more samples per samplinginterval with sufficient observation locations to check uniformity of sample. The pixel size of the LSCM images is 512 pixels by 512 pixels. The optical slices of each specimen were carefully analyzed and representative imageslocated at proper z-positionare presented.

AFM topographical images were acquired by using a Dimension Icon $^{\circledR}$ AFM (Bruker) with PeakForce QNM ${ }^{\circledR}$ (Quantitative Nanomechanical Property Mapping) based on peak force tapping mode. An antimony doped silicon probe with reflective aluminum back side coating (RTESPA, Bruker) was used. The probe spring constant is $40 \mathrm{~N} / \mathrm{m} \pm 5$ $\mathrm{N} / \mathrm{m}$ with resonant frequency of approximately $300 \mathrm{kHz}$. Scan size of $25 \mu \mathrm{m} \times 25 \mu \mathrm{m}$ with scan speed of $0.5 \mathrm{~Hz}$ was performed at ambient conditions.

\subsection{Raman imaging}

Raman imaging was performed on a Senterra Raman microscope with a high-precision motorized XYZ stage controlled by OPUS 7 software (Bruker). The optical configuration of the Raman microscope is dispersive and $180^{\circ}$ back scattering coupled with a charge-coupled device (CCD) camera for bright field imaging. An excitation wavelength of $785 \mathrm{~nm}$ was provided by a diode laser. The laser power, number of scans and integration time used were in the ranges of (25 to 50$) \mathrm{mW}$, (1 to 5) scans, and (10 to 20) sec, respectively. A 50x metallurgical objective (N.A.=0.75, MPlan, Olympus) was used for mapping, and the spatial resolution and laser spot size were estimated to be $0.5 \mu \mathrm{m}$ and $2 \mu \mathrm{m}$, respectively [22]. A high throughput slit aperture of $50 \mu \mathrm{m} \times 1000 \mu \mathrm{m}$ was utilized to shorten the time of mapping. Raman spectrawere collected in the wavelength range of $70 \mathrm{~cm}^{-1}$ to $3200 \mathrm{~cm}^{-1}$. Raman mapping images were constructed in user-defined desired areas $(170 \mu \mathrm{m} \times 50 \mu \mathrm{m}$ to $100 \mu \mathrm{m} \times 50 \mu \mathrm{m})$ on the 
sample cross-section with a step size of $2 \mu \mathrm{m} \pm 0.01 \mu \mathrm{m}$, so that each Raman image contains thousands of Raman spectra. Individual Raman images were taken from different regions centered at the PET outer layer, PET core layer and EVA layers. All mapping was performed under room temperature. Note that care was taken to make sure microscopic optical axis was normal to sample cross-section, and laser parameters andfocus on sample cross-section were kept the same for each mapping layer/material in order to comparespectrum intensitybetween samples [26]. The standard uncertaintyis \pm 3 $\mathrm{cm}^{-1}$ inwavenumber, and the relative standard uncertainty is $\pm 5 \%$ in intensity.

OPUS 7 software was used for further processing of Raman spectra andimages. Firstly, Raman spectra were inspected to determine the location of the interface between layers, and then Raman images were trimmed for each layer and/or each material. The layer/material thickness presented in each trimmed Raman image is smaller than the actual thickness by $6 \mu \mathrm{m} \pm 2 \mu \mathrm{m}$ due to the laser spot size of Raman microscope. Two types of Raman imageswere acquired: one is based on spatial intensity distribution of fluorescence emission and the other on characteristic Raman peaks. To analyze the evolution of certain characteristic bands for chemical information, the fluorescence emission was subtracted using a method of endpoint constrained polynomialfittingprovided in the OPUS 7 software. All fluorescence emission-subtractedspectra were carefully inspected to ensure no significant artifacts caused from the operation of subtraction. Note that the scaling of Raman images is shown as " 0 to 1 ", which is the normalized scale based on the maximum intensity in the same image. However, the intensity shown in line profiles is the raw intensity, not the normalized value [27].Raman spectra and images were then analyzed for chemical degradation profiling.It was found that the relative standard uncertainty of intensity 
associated with spatial measurement strongly depends on aging conditions.Instead of standard deviation, all of the measurement data are presented at each depth location for line profile results unless stated otherwise.

\section{Results and discussion}

\subsection{Structure of the PPE backsheet film}

ALSCM image of the cryo-microtomed cross-section of fresh PPE backsheet is shown in Figure 1. Combined with the chemical information provided by Raman spectra of each individual layer (Figure 2), it is suggested that the PPE backsheetis comprised of five main layers, aPET outer layer, a PET core layer, an EVA inner layer, a pigmented-EVA layer and an EVA outer layer, along with two visible adhesive layers between PET outer and PET core layers (designated as PET/PET adhesive), and PET core and EVA inner layers (designated as PET/EVA adhesive). The thicknesses measured from the LSCM image for each layer are approximately $55 \mu \mathrm{m}, 126 \mu \mathrm{m}, 25 \mu \mathrm{m}, 50 \mu \mathrm{m}, 25 \mu \mathrm{m}$, $6.5 \mu \mathrm{m}$, and $8 \mu \mathrm{m}$ for PET outer, PET core, EVA inner, pigmented-EVA, EVA outer, PET/PET adhesive, and PET/EVA adhesive, respectively. Similar thickness values for each layer can be obtained from Raman images. However, due topixel size, the thickness values obtained by Raman imaging are slightly smaller, at least $4 \mu \mathrm{m}$, than those obtained by LSCM.It is worth mentioning that the PET outer layer is heavily pigmented, while the PET core layer is lightly pigmented, as shown in the LSCM image and the Raman spectra discussed later.The randomly distributed dark spots on PET core layer in Figure 1are probably due to the aggregation of pigments.

Figure 2 shows the raw (as collected) Raman spectra for each layer of fresh PPE backsheet. As seen in Figure 2(a), the Raman spectra of both PET outer and core layers 
are quite similar. Table 1 gives the assignments of typical bands of PET Raman spectra[18,28-30]. The main characteristic bands of PET that are utilized for the study of degradation are the carbonyl $(\mathrm{C}=\mathrm{O})$ stretching at1726 $\mathrm{cm}^{-1}$, and a group of bands at $1115 \mathrm{~cm}^{-1}, 1094 \mathrm{~cm}^{-1}$, and $998 \mathrm{~cm}^{-1}$, whichare commonly attributed to mixed modesof ring $\mathrm{CH}$ in-plane bending, glycol $\mathrm{C}-\mathrm{O}$ stretching, $\mathrm{COC}$ and $\mathrm{CCO}$ bending, and $\mathrm{C}-\mathrm{C}$ stretching of PET.The bands at $454 \mathrm{~cm}^{-1}$ and $990 \mathrm{~cm}^{-1}$ shown in the inset of Figure 2(a) for the PET outer layer are attributed to barium sulfate $[31,32]$. The presence of these bands suggeststhat the PET outer layer is filled with barium sulfatepigments. Bands in the region of $950 \mathrm{~cm}^{-1}$ to $1200 \mathrm{~cm}^{-1}$ of a PET material (see inset of Figure 2(a)) have been reported to be associated with its conformation and crystallinity [30]. Later in this paper, we will use the intensity ratio of the bands at $1094 \mathrm{~cm}^{-1}$ and $1115 \mathrm{~cm}^{-1}$ to evaluate the changes in PET crystallinity after UV exposure.

Raman spectra of the PET/PETand PET/EVA adhesive layers are displayed in Figure 2(b). These Raman spectra suggest thatthe adhesives are based on polyurethane, as evidenced by the strong band at $1445 \mathrm{~cm}^{-1}$ and the shoulder at $1242 \mathrm{~cm}^{-1}$ for isocyanate, $\mathrm{N}-\mathrm{H}$, and urethane amide III $[33,34]$. Based on the characteristic $\mathrm{C}=\mathrm{O}$ and $\operatorname{ring} \mathrm{C}=\mathrm{C}$ bands at $1726 \mathrm{~cm}^{-1}$ and $1614 \mathrm{~cm}^{-1}$, respectively, we suggest that the main composition of the polymer matrix of the adhesives is an aromatic polyester-based polyurethane. The characteristic bands at $941 \mathrm{~cm}^{-1}, 765 \mathrm{~cm}^{-1}$, and $656 \mathrm{~cm}^{-1}$ are the proof of silane coupling agents such as $\quad \gamma$-glycidoxypropyl-trimethoxysilane (GPTS) and $\gamma$-aminopropyl-triethoxysilane (APTS) [35], which are commonly used as adhesion promoters in adhesives.In addition, the small but distinctiveP-O band at $1180 \mathrm{~cm}^{-1}$ indicates the presence of phosphorus-oxyacid-based antioxidants in the formulation[5,36]. Comparing the $\mathrm{CH}$ ranges from $2850 \mathrm{~cm}^{-1}$ to $3200 \mathrm{~cm}^{-1}$ between the two spectra, it is 
believed that there are some formulation differences between the PET/PET and PET/EVA adhesives. However, due to the proprietary information of the backsheet, the details of these differences are not known.

Raman spectra of the EVA layers of the PPE backsheet are shown in Figure 2(c), and the assignments of thebands are givenin Table 2.The $\mathrm{C}=\mathrm{O}$ stretching around $1727 \mathrm{~cm}^{-1}$ is solely from vinyl acetate (VA) of the EVA copolymer [37,38]. The relative intensity of thisband with respect to that of $1461 \mathrm{~cm}^{-1}$ (due to ethylene $\mathrm{CH}_{2}$ rocking) provides information aboutthe relative content of VA in the EVA copolymer. The EVA outer layer hada lower VA content than the EVA inner layer and pigmented-EVA layer. Generally, a lower VA content in EVA tends to bring about a higher value of melting pointor modulus, buta lower adhesion strength[41,42]. Different VA componentsused in variousEVA layers may be due to the need of processing, cost and performance. The pigmented-EVA shows two characteristic bands at $609 \mathrm{~cm}^{-1}$ and $446 \mathrm{~cm}^{-1}$, assigned to the Ti-O bonds $[43,44]$,indicatingthat rutile titanium dioxidewasused for enhancing the UV reflectivity(albedo)of the film.Additionally, the definedC $=\mathrm{C}$ stretching band at $1614 \mathrm{~cm}^{-1}$ is probably due to aromatic additives in the formulated EVA, while the detailed proprietary information is not known.

\subsection{Degradation profiles and interfacial microscopies}

\subsubsection{Raman spectraand mapping}

Examples of one-dimensional Raman mapping spectra, which are the constructing elements of the Raman images, aredisplayed in Figure 3. Figure 3(a)shows a set of raw Raman spectra as a function of depth of the PET outer layer after $1600 \mathrm{~h}$ aging underUV $/ 85^{\circ} \mathrm{C} / 5 \%$ RH.Each spectrum has its spatial location corresponding to the 
position of the PET outer layer cross-section, where the top spectrum L was taken fromasite close to the exposed surface while the bottom spectrum A was from a site close to the adhesive layer between PET outer layer and core layer (see inset in Figure 3(a)). The spectrum of the fresh PET outer layer before exposure is also shown as a reference. The intensity of the fluorescent emissionbackgroundsequentially changes as a function of the sample depth, specifically, the closer to the UV-exposedsurface, the higher the background emission intensity. Figure 3(b) presents the same set of spectra but after the baseline correction to eliminatethe fluorescence emission.

Asstated in the experimental section,there aretwo types of Raman images presentedin this study. One is based on the intensity of the background fluorescenceemission from the raw Raman spectra (i.e.Figure 3(a)), the other is based onthe intensity of the specific Raman band after subtractingthe background fluorescence emission (i.e. Figure 3(b)). The former, namely as fluorescence emission image, is generally related to the amount of chromophores (additives, discoloration products, etc.) due to the nature of the conjugated structuresof mostfluorescent materials. The latter, namely as Raman image,provides information about chemical or physical structural changes during UV exposure, because the selected bands are those representing the intrinsic structures of the materials and are sensitive to aging.

\subsubsection{PET outer layer}

Two types of Raman images of the PET outer layer after $1600 \mathrm{~h}$ agingin $\mathrm{UV} / 85^{\circ} \mathrm{C}$ at two humidity levelsand their corresponding Ramanintensity line profile are displayed in Figures 4(a) to 4(d) and Figures 4(e) to 4(f), respectively. The intensity at $1660 \mathrm{~cm}^{-1}$ was chosen as an index of the fluorescence emissionfor the fluorescence imagingbecause no visible Raman absorption was observed at $1660 \mathrm{~cm}^{-1}$ and therefore, the intensity of this 
band could be assigned to the fluorescence emission solely. The red region of the fluorescence images in Figures 4(a) and 4(c) indicates that the UV exposed outermost region of the PET outer layer has a higher fluorescence emission than the blue central region. This is consistent with our observation of yellowing on the surface of the UV-exposed PPE(yellowing data not shown in this article). The sample aged in dry conditionsshows a gradual decrease influorescenceemission from the surface to the bulk(Figures 4(a) and 4(e)), while thataged in humidconditions presents a much higher but a sharperdecreasein fluorescenceintensitynear the exposedsurface(Figures 4(c) and 4(e)). This result indicates that moisture diffusionaffects the profileof thefluorescence emission in the PET outer layer, and damage by moisture seems to beconfined mainlynear the surface region.Moreover, this implies that thePET outer layer of this multilayer PPE backsheetmight be hydrolysis-resistant by end-group capper, as designed for most PET-based backsheets. Note that fluorescence is generated not only by the degradation of PET polymer matrix but also by the deterioration ofadditives/pigments such as UV stabilizers, absorbers, and inorganic $\mathrm{BaSO}_{4}$ pigments during the exposure.

Photo-degradation of PET generally involves the ether bond cleavage of the ester groups to yield carboxylic acid, aldehyde and other volatile small molecules such as $\mathrm{CO}_{2}$ $[7,8,18]$.Raman images of the PET outer layer constructed usingthe ester $\mathrm{C}=\mathrm{O}$ Raman band to map the degradation of PETareillustrated in Figures 4(b) and 4(d).The blue region near the surface indicatesthat the amount of ester groups in the surface regionis much lower than thatin the central region for the aged PET outer layer, and the quantitative change in the intensity can be seen from a line profile of $\mathrm{C}=\mathrm{Oacross}$ the thickness of PET outer layer shown in Figure 4(f). These results suggest thatsevere degradation has occurred near the UV exposed surface of the PET outer layer, and the 
region of decreased ester groups wasextended up toapproximately $20 \mu \mathrm{m}$ from the surface in both dryand humid exposure conditions, with the most severe changes occurring in the top $10 \mu \mathrm{m}$ from the exposed surface (Figure 4(f)). Figure 4(f) also reveals that the loss of the ester $\mathrm{C}=\mathrm{O}$ bandfor samples aged at dry and humidconditions are similar. This result implies that UV radiation is the main factor responsible for thedegradation process of the PET outer layer,compared to theeffects of moisture, especially for the hydrolysis-resistant PPE. However, the low sensitivity of Raman signal to the carbonyl groups due to the large dipole moment of the groups also gives challenges to identify the degradation products such as acid, aldehyde from ester based on $\mathrm{C}=\mathrm{O}$ stretching vibration.A supplemental test, attenuated total reflection Fourier transform infrared spectroscopy (ATR-FTIR), on the same sample showed that the moisture affected the photodegradation of the PET outer layer (data not shown). However, the UV irradiation is still the dominant factor.

Furthermore, a thickness reduction was observed for the aged PET outer layer. The thickness of fresh PET outer layer is about $55 \mu \mathrm{m}$ (see Figure 1), while the thicknesses of both dry and humidconditionsaged PET outer layers are about $42 \mu \mathrm{m}$ plus $6 \mu \mathrm{m} \pm 2 \mu \mathrm{mif}$ considering the laser spot size of Raman microscope. The thickness decrease in both dry and humid conditions as observed by LSCM is also consistent with Raman intensity line profile results shown in Figures4(e) and 4(f). Such thickness reduction is common for the polymers during degradation[45] due to loss of volatile materials resulting from chemical degradation, and physical erosionof degraded products and pigments.

Figure 5 shows the depth-dependent evolution of Raman spectra of PET outer layerin the range of $950 \mathrm{~cm}^{-1}$ to $1230 \mathrm{~cm}^{-1}$. It has beenreported that during hydrolytic and 
photolytic degradation, changes in the crystallinity of PET could take place along with chemical degradation [8,46].According toFigure 5(c), using the intensity ratio between the bands at $1094 \mathrm{~cm}^{-1}$ and $1115 \mathrm{~cm}^{-1}\left(\mathrm{I}_{1094} / \mathrm{I}_{1115}\right)$, which is representative of relative concentration of trans-glycol conformers[29,47], we have investigated the crystallinity change of PET after UV exposure in dry and humid conditions. A lower intensity ratio of $\mathrm{I}_{1094} / \mathrm{I}_{1115}$ generally corresponds to a lowercrystallinity. The value of $\mathrm{I}_{1094} / \mathrm{I}_{1115}$ decreasesfrom bulk to the exposed surface in the PET outer layer, suggesting that the crystallinity of PET near the surface region becomes lower after aging.A similar trend is observed for samples exposedin dry or humid conditions.However,the appearance of a sharp Raman shift of $\mathrm{BaSO}_{4}$ pigments $\left(990 \mathrm{~cm}^{-1}\right)$ near the humid exposed surface in Figure 5(b)suggests that the surface agedin humid conditions is enriched with $\mathrm{BaSO}_{4}$ pigments. The appearance of the new bands at $1040 \mathrm{~cm}^{-1}$ and $1050 \mathrm{~cm}^{-1}$ indicates that a secondary reaction of degraded products with moisture might haveoccurred, however, the origin of those productsis not certain.

\subsubsection{PET core layer}

Figures 6(a) to 6(c) present the Raman imagesof the ester $\mathrm{C}=\mathrm{O}$ intensity of theunaged, andaged PET core layersexposed in dry and humidconditions. The profiles of the ester $\mathrm{C}=\mathrm{O}$ for both aged samples are similar to that of the unagedsample, which hasan overall uniform contrastwith some random heterogeneity across the whole PET core layer. This result suggests that the PET outer layer has effectively blocked the UV irradiation, and the degradation of PET core layer wasmostly dominated by relatively uniform thermal degradation in the multilayer system. Note that the thermal degradation effect was further confirmed by Raman spectra as shown in Figure 7. Random low $\mathrm{C}=\mathrm{O}$ intensity (blue) spots in theseRaman images are probably caused by aggregation of 
pigments as mentioned abovein Figure 1.

However, a careful examination of Figure 6(c)reveals that there is anarrow but distinct low $\mathrm{C}=\mathrm{O}$ intensity region near theEVA side exposed in humid conditions(leftin Figure 6(c)). The fluorescence emissionimage in Figure 6(d) provides additional evidence of changes in this vicinity. The strong red contrast implies that the species with high fluorescence emission are formed in the PET core layer near the EVA side. The results are probably related to the moisture effect on PET degradation or/and the possible additive migration between the interfacial region between PET core layer and EVA inner layer. Additional information about the effect of moisture on the PET core layer can also be seen from the Raman spectrataken along the thickness of this layer(Figure 7). Compared to the fresh sample, the fluorescence emissionof the samples aged in dry conditionswasslightly and evenly enhanced, but a more progressive, increased fluorescence wasseenfor those aged in humid conditions, especially when the location is closer to the EVA side. The Raman image shown in Figure 6(d) clearly presents such evolution of the fluorescenceemission with the depth.

\subsubsection{AFM images and Raman spectra of interfaces of PET Outer/PET Core layers and}

\section{PET Core/EVA layers}

To better understandwhy the PET core layer experienced different aging effects on itsopposing sides, AFM topographical images were acquired intwo interfacial regionsfor both aged and unaged samples: between PET outer and PET core layers (Figures 8(a), 8(c), and 8(e)), and between PET core and EVA inner layers (Figures 8(b), 8(d), and 8(f)).The dark and bright color regions in Figure 8 correspond to areas below and above the surface, respectively.Before exposure, eachregion exhibits an adhesive layerfeatured with many small nodules, similar to latex structures from emulsion polymerization. 
However, after aging,the nodular structure wassubstantially diminished, andthickness reduction of the adhesive layers took place, particularly for samples aged in humid conditions. Agroove-like structure of aged samples indicatesasubstantial loss of materials. For the PET/PET adhesive, such loss is further confirmed by itsRaman spectra (Figure 9), showing intensity loss of the polyurethanebands at $1445 \mathrm{~cm}^{-1}$ and $1242 \mathrm{~cm}^{-1}$, as well as the loss of some additives such as silane $\left(656 \mathrm{~cm}^{-1}\right)$ [48-50]after aging in humid conditions. It was also found that the adhesive layers were soft and easily smearedduring microtomingafter aging in humid conditions, and the narrowing of the PET/PET adhesive layer after aging in humid conditions(Figure 8(e)) made it difficult to acquire Raman spectraof the adhesive-only layers without interference from the PET sides.Chemical and morphological changesnear or in the PET/PET interfacial region (Figures 8 and 9) may be attributed to several phenomena, including thermal and hydrolytic degradation of the adhesive layers,further coalescence of the latex-likemicrostructures, and diffusion of water-soluble molecules and degradation products from the adhesive to the PET layer near the interface. It should be mentioned that polar molecules and hydrophilic surfactants and additives have a strong affinity for water. During exposure to water or high humidity, these materials tend to migrate to the hydrophilic interface, which attract multiple monolayers of water and cause loss of adhesion[51]. Hence,the changes of the PET/PET and PET/EVA interfacial regions are probably resulting from the susceptibility of the adhesive layers to moisture at elevated temperature. That may also influence the non-uniform degradation of PET core layer near the EVA side in humid conditions.

\subsubsection{EVA layers}

EVA layers were on the back side of PPE samples during the UV exposure, and the 
EVA outer layer was directly exposed to moisture. Because of the low intensity of $\mathrm{C}=\mathrm{O}$ band in the EVA, integration of aliphatic $\mathrm{CH}$ band region from $2800 \mathrm{~cm}^{-1}$ to $3000 \mathrm{~cm}^{-1}$ of the Raman spectra was chosen for the study of EVAdegradation [10]. Figures 10(a) through 10(c) show Raman images of the EVA layers based on the aliphatic $\mathrm{CH}$ band intensity (fluorescence emission-subtracted) before aging and after aging in dry and humid conditions. Figures 10(e) and 10(f) are intensity line profiles for the aliphatic $\mathrm{CH}$ band and fluorescence emission.From the results of Figure 10, the following observations are made: (1) the lower aliphatic $\mathrm{CH}$ intensity (blue regions in Figures10(a) to 10(c)) of the pigmented-EVA layer in comparison to other EVA layers is due to reducedaliphatic $\mathrm{CH}$ concentration in the presence of $\mathrm{TiO}_{2}$ pigments; (2) the distribution profile of aliphatic $\mathrm{CH}$ intensity across three EVA layers for the sample aged in dry conditions is similar to that of the fresh sample; onlya slight difference in the EVA inner layer or outer layers, probably due to thermal aging; (3) in humid conditions, the thickness of the pigmented-EVA layer is dramatically decreased, and the aliphatic $\mathrm{CH}$ intensity in this layer is much lower than the fresh and the dry aged samples; these changes may be due to water-assisted degradation of pigmented-EVA, a detailed mechanism is not yet clear due to proprietary information; (4) the strong contrast in Raman image (Figure 10(d)) and the markedlyhigh intensity of the fluorescenceemission (Figure 10(f)) observedin the $\mathrm{TiO}_{2}$-pigmented-EVA layer suggests the formation of higher emission species in this layer during exposure in humid conditions.The reaction to form these higher emission species may involve the pigments,moisture,or EVA and/or their combination.Pigments mayaccelerate the EVA degradation in the presence of moisture. One postulation could be related to the acid-base reaction between acetic acid resulting from EVA degradation [4-6,8] and the basic nature of $\mathrm{TiO}_{2}$ surface with high moisture. In summary, degradation 
in the three-layered EVA structuresis localized due to different compositions of each layer.

\subsection{Backsheet failure assessment}

When combining the degradation profiles of the entire PPE multilayers, it is found that the most damaged regions are the PET outer layer, pigmented-EVA layer, and the two adhesive layers.Severe degradation of pigmented-EVA layer is responsible for visible yellowing observed (yellowing data not shown in this article)on the EVA side of PPE backsheet. To assess the failure mode of the PPE backsheet, weathering tests with prolonged exposure time up to $3280 \mathrm{~h}$ were performedunder similar weathering conditions [2]. As seen in Figure 11, the exposure surface of PET outer layer has experienced significant crack development during aging; visible holes/cracks were observed after $1600 \mathrm{~h}$ in humidconditions, while there were no significant changes even after $2500 \mathrm{~h}$ in dry conditions. After $3280 \mathrm{~h}$ exposure, the propagation of the cracks in humid conditions was more severe as well (Figures 11(c) vs. 11(e)). Furthermore, a spontaneous delaminationbetween PET outer and PET core layers was observed during exposure in humidconditions (Figure 11(f)). Note that there wasno delamination observed in dry conditions, nor for EVA layers due to the nature of its self-priming. This indicates that the adhesive layer between PET outer and PET core layers become the weakest region in the multilayers during aging with humidity. This is consistent with the results of AFM imaging and Raman spectra of the region (Figures 8 and 9), showing dramatic degradation occurringbetween PET outer layer and PET core layer.

In addition,as shown in Figure 11(f), it should be notedthatthe delaminated PET outer layer presents high internal residual stress according to its upward curled shape with 
a significant curvature [52]. The curling direction indicates that the internal stress distributionin the PET outer layer is in tension near the exposure surface side.Based on thedegradation profile shown in Figures 4(a) and 4(c), and the radius of curvature of PET outer layer, the average internal stress of the PET layer can be relatively estimated by a modified Stoney's equation describing the internal stress of the sharp degraded region [53]. Using this approach,the mode I stress intensity factor for PET exposed in humid conditions is approximately an order magnitude greater than that aged in dry conditions.As a result, the exposed surface of PET outer layer is moreprone to form cracks after aging in humidconditions. The details ofthis study will be published in the future.

\section{Conclusions}

We have applied Raman spectroscopic imaging to investigate the degradation profile in each layer of a commercial multilayer PPE backsheet after aging in $300 \mathrm{~nm}$ to $400 \mathrm{~nm}$ UV at $85{ }^{\circ} \mathrm{C}$ and two RH levels, $5 \%$ and $60 \%$, for $1600 \mathrm{~h}$. Cryo-micromed cross-sections of the aged multilayer backsheet were used for degradation depth profiling. Both Raman and fluorescence emission signals obtained in a Raman spectrum were utilized for imaging, and laser scanning confocal and atomic force microscopies were employed to aid in the analyses. It was found that non-uniform degradation took place in the aged backsheet films, and both UV and moisture significantly affected degradation of the multilayers. Severe degradation occurred on the outmost region of the pigmented PET outer layer and the degradation gradient extended to approximately $20 \mu \mathrm{m}$ to the bulk. The most susceptible regions in the PPE multilayer were the PET outer layer, pigmented-EVA layer, and the two adhesive layers. Severe degradation of 
pigmented-EVA layer was responsible for visible yellowing on the EVA side of PPE backsheet. Furthermore, cracking was also observed on the exposure surface of the PET outer layer, and this cracking behavior was strongly dependent on the humidity of the aging condition. Complete delamination between the PET/PET layers after prolonged exposure $(3280 \mathrm{~h})$ in humid conditions was also observed. This is consistent with the marked degradation observed in AFM and Raman imaging. The upward curling direction of the delamination suggested a residual internal stress distribution in the PET outer layer, and the magnitude of this internal stress can be relatively quantified. In summary, degradation depth profile results indicated that Raman imaging can provide useful data on the chemical degradation along the thickness of a multilayer PPE backsheet. Degradation depth-profiling presented in this study should provide insights to failure mechanisms of multilayer backsheet used in photovoltaic modules during weathering. 


\section{Acknowledgements}

This work was conducted with the support of the NIST/Industry PV materials consortium. The authors thank all members of this consortium for the helpful discussions. Appreciation is extended to Dr. Tinh Nguyen and Dr. Lipiin Sung at NIST for their discussion and suggestion throughout this work.

\section{References}

[1] G.J. Jorgensen, K.M. Terwilliger, J.A. DelCueto, S.H. Glick,M.D. Kempe, J.W. Pankow, F.J. Pern, T.J. McMahon,Moisture transport, adhesion, and corrosion protection of PV module packaging materials, Sol. Energy Mat. Sol. Cells90(2006) 2739-2775.

[2] W. Gambogi, Y. Heta, K. Hashimoto, J. Kopchick, T. Felder, S. MacMaster, A. Bradley,B. Hamzavytehrany, V. Felix, T. Aoki, K. Stika, L. Garreau-Illes, T.J. Trout, Weathering and durability of PV backsheets and impact on PV module performance, in: Proceedingsof SPIE, 8825 (2013)88250B.

[3] G. Oreski, G.M.Wallner, Delamination behaviour of multi-layer films for PV encapsulation, Sol. Energy Mat. Sol. Cells 89 (2005) 139-151.

[4] F.J.Pern,Luminescence and absorption characterizationof ethylene-vinyl acetate encapsulant for PVmodules before and after weatheringdegradation, Polym. Degrad. Stab. 41 (1993) 125-139.

[5] F.J.Pern,Ethylenevinylacetate(EVA)encapsulantsforphotovoltaicmodules: degradation anddiscolorationmechanismsandformulationofimproved photostability,DieAngewandteMakromolekulareChemie252(4523)(1997) 195-216.

[6] P.Klemchuk,M.Ezrin,G.Lavigne,W.Holley,J.Galica,S.Agro,Investigationof the degradationandstabilizationofEVA-basedencapsulantin field-aged solar energy modules,Polym.Degrad.Stab.55(1997)347-365.

[7] G.J.M.Fechine, M.S.Rabello, R.M.SoutoMaior, L.H.Catalani,Surface characterization of photodegraded poly(ethylene terephthalate). The effect of ultraviolet absorbers, Polymer 45 (2004) 2303-2308.

[8] G.J.M.Fechine, M.S.Rabello, R.M.Souto-Maior,The effect of ultraviolet stabilizers on the photodegradation ofpoly(ethylene terephthalate), Polym.Degrad.Stab. 75(2002) 153-159. 
[9] J. Schlothauer, S. Jungwirth, M. Köhl, B. Röder, Degradation of the encapsulant polymer in outdoor weathered photovoltaic modules: Spatially resolved inspection of EVA ageing by fluorescence and correlation to electroluminescence, Sol. Energy Mat. Sol. Cells102 (2012) 75-85.

[10] C.Peike, T.Kaltenbach, K.-A.Wei $\beta$, M.Koehl, Non-destructive degradation analysis of encapsulants in PV modules by Raman spectroscopy, Sol. Energy Mat. Sol. Cells 95(2011)1686-1693.

[11] K. Grabmayer, G.M. Wallner, S. Beißmann, J. Schlothauer, R. Steffen, D. Nitsche, B.Röder, W. Buchberger, R.W. Lang, Characterization of the aging behavior of polyethylene byphotoluminescence spectroscopy, Polym.Degrad.Stab. 107 (2014) 28-36.

[12] D.Wu, J.Zhu, T.R.Betts, R.Gottschalg, Degradation of interfacial adhesion strength within photovoltaic mini-modules during damp-heat exposure, Prog. Photovolt.: Res. Appl. 22 (2014) 796-809.

[13] F.D.Novoa, D.C.Miller, R.H.Dauskardt, Environmental mechanisms of debonding in photovoltaic backsheets, Sol. Energy Mat. Sol. Cells 120 (2014) 87-93.

[14] F. Liu, L. Jiang, S. Yang,Ultra-violet degradation behavior of polymeric backsheets for photovoltaic modules, Sol. Energy 108 (2014) 88-100.

[15] N.Kim, H.Kang, K.-J.Hwang, C.Han,W.S.Hong, D.Kim, E.Lyu, H.Kim, Study on the degradation of different types of backsheets used in PV module under accelerated conditions, Sol. Energy Mat. Sol. Cells 120 (2014) 543-548.

[16] H. Li, R. Kikuchi, M. Kumagai, T. Amano, H. Tang, J.-M. Lin, K. Fujiwara, N. Ogawa,

Nondestructiveestimationofstrengthdeteriorationinphotovoltaicbacksheetsusingaport ablenearinfraredspectrometer, Sol. Energy Mat. Sol. Cells 101 (2012) 166-169.

[17] Y.Voronko, B.S.Chernev, G.C.Eder, Spectroscopic investigations on thin adhesive layers in multi-material laminates, Appl. Spectrosc. 68 (2014) 584-592.

[18] E.Planes, B.Yrieix, C.Bas, L.Flandin, Chemical degradation of the encapsulation system in flexible PV panel as revealed by IR and Raman microscopies, Sol. Energy Mat. Sol. Cells 122 (2014) 15-23.

[19] X.Gu, C.A.Michaels, P.L.Drzal, J.Jasmin, D.Martin, T.Nguyen,J.W.Martin, Probing photodegradation beneath the surface: a depth profiling study of UV-degraded polymeric coatings with microchemical imaging and nanoindentation, J. Coat. Technol. Res. 4 (2007) 389-399.

[20] A.M.Forster,C.A.Michaels, L.Sung, J.Lucas, Modulus and chemical mapping of 
multilayer coatings, ACS Appl. Mater. Interfaces 1 (2009) 597-603.

[21] R. Appel, T.W. Zerda, W.H. Waddell, Raman microimaging of polymer blends,Appl. Spectrosc. 54 (2000) 1559-1566.

[22] A. Zoubir (Ed.), Raman Imaging, Springer, Verlag Berlin Heidelberg, 2012.

[23] N. Phillips, K. Scott, (2014)http://www.nrel.gov/pv/pdfs/2014_pvmrw_72_atlas.pdf; also see http://www.nist.gov/el/building_materials/upload/Phillips.pdf

[24] J.Chin, E.Byrd, N.Embree, J.Garver, B.Dickens, T.Finn, J.Martin, Accelerated UV weathering device based on integrating sphere technology, Rev. Sci. Instrum. 75 (2004) 4951-4959.

[25] T.J. Young, M.A. Monclus, T.L. Burnett, W.R. Broughton, S.L. Ogin, P.A. Smith,

The use of the PeakForce ${ }^{\mathrm{TM}}$ quantitative nanomechanical mapping AFM-based method for high-resolution Young's moduluss measurement of polymers, Meas. Sci.

Technol. 22 (2011) 125703.

[26] V. Presser, M. Keuper, C. Berthold, K.G. Nickel, Experimental determination of the Raman sampling depth in zirconia ceramics, Appl. Spectrosc. 63 (2009) 1288-1292.

[27] L. Ashton, K.A. Hollywood, R. Goodacre, Making colourful sense of Raman images of single cells, Analyst, 140 (2015) 1852-1858.

[28]Th.Lippert, F.Zimmermann, A.Wokaun, Surface analysis of excimer-laser-treated polyethylene-terephthalate by surface-enhanced Raman scattering and x-ray photoelectron spectroscopy, Appl. Spectrosc. 47 (1993)1931-1942.

[29] I.M.Ward, M.A.Wilding, Infra-red and Raman spectra of poly $(m$-methylene terephthalate) polymers, Polymer 18 (1977)327-335.

[30] F.Adar, H.Noether, Raman microprobe spectra of spin-oriented and drawn filaments of poly(ethylene terephthalate), Polymer 26 (1985) 1935-1943.

[31] S.G.Harroun, J.Bergman, E.Jablonski,C.L.Brosseau, Surface-enhanced Raman spectroscopy analysis of house paint and wallpaper samples from an $18^{\text {th }}$ century historic property, Analyst 136 (2011) 3453-3460.

[32] Ch. Srilakshmi, E. Widjaja, M. Garland, B.G. Anderson, Deconvolution of pure component FT-Raman spectra from thermal emission of barium sulfate and graphite samples using the BTEM algorithm, J. Raman Spectrosc. 38 (2007) 349-355.

[33] S.Parnell, K.Min, M.Cakmak, Kinetic studies of polyurethane polymerization with Raman spectroscopy, Polymer 44(2003) 5137-5144.

[34] N.Roohpour, J.M.Wasikiewicz, D.Paul, P.Vadgama, I.U.Rehman, Synthesis and characterization of enhanced barrier polyurethane for encapsulation of implantable medical devices, J. Mater. Sci.: Mater. Med. 20(2009)1803-1814. 
[35] P.T.K.Shih, J.L. Koenig, Raman studies of silanecoupling agents, Mater. Sci. Eng. 20 (1975) 145-154.

[36] M. Tsuboi, Vibrational spectra of phosphite and hypophosphite anions, and the characteristic frequencies of $\mathrm{PO}_{3}$--and $\mathrm{PO}_{2}$-groups, J. Am. Chem. Soc. 79 (1957) 1351-1354.

[37] M.Shimoyama, H.Maeda, K.Matsukawa, H.Inoue, T.Ninomiya, Y.Ozaki, Discrimination of ethylene/vinyl acetate copolymers with different composition and prediction of the vinyl acetate content in the copolymers using Fourier-transform Raman spectroscopy and multivariate data analysis, Vib. Spectrosc. 14(1997)253-259 .

[38] Y.Ren, M.Shimoyama, T.Ninomiya, K.Matsukawa, H.Inoue, I.Noda, Y.Ozaki, Two-dimensional Fourier transform Raman correlation spectroscopy study of composition-induced structural changes in a series of ethylene/vinyl acetate copolymers, J. Phys. Chem. B 103(1999) 6475-6483.

[39] A.M.Macdonald,A.S.Vaughan, P.Wyeth, Application of confocal Raman spectroscopy to thin polymer layers on highly scattering substrates: A case study of synthetic adhesives on historic textiles, J. Raman Spectrosc. 36(2005) 185-191.

[40] B.S.Chernev, C.Hirschl, G.C.Eder, Non-destructive determination of ethylene vinyl acetate cross-linking in photovoltaic (PV) modules by Raman spectroscopy, Appl. Spectrosc. 67(2013) 1296-1301.

[41] J. Kim, J. Wang, H.-J. Kang, F. Talke, A study of nano-mechanical and macro-mechanical properties of ethylene vinyl acetate, Polym. Eng. Sci. 48 (2008) 277-282.

[42] Y.T. Sung, C.K. Kum, H.S. Lee, J.S. Kim, H.G. Yoon, W.N. Kim, Effects of crystallinity and crosslinking on the thermal and rheologicalproperties of ethylene vinyl acetate copolymer, Polymer 46 (2005) 11844-11848.

[43] C. Aprile, L. Maretti, M. Alvaro, J.C. Scaiano, H. Garcia, Long-lived (minutes) photoinduced charge separation in a structured periodicmesoporoustitania containing 2,4,6-triphenylpyrylium as guest, Dalton Trans. (2008) 5465-5470.

[44] J. Zhang, M. Li, Z. Feng, J. Chen, C. Li, UV Raman spectroscopic study on $\mathrm{TiO}_{2}$. I. Phase transformation at the surface and in thebulk, J. Phys. Chem. B 110 (2006) 927-935.

[45] A. Rezig, T. Nguyen, D. Martin, L. Sung, X. Gu, J. Jasmin, J.W. Martin,Relationship between chemical degradation and thickness loss of an amine-cured epoxy coating exposed to different UV environments, J. Coat. Technol. Res. 3 (2006) 173-184. 
[46] C. Sammon, J. Yarwood, N. Everall, An FT-IR study of the effect of hydrolytic degradation on the structure of thin PET films, Polym.Degrad.Stab. 67 (2000) 149-158.

[47] J.Štokr, B.Schneider, D.Doskočilová, J.Lövy, P.Sedláček, Conformational structure of poly(ethylene terephthalate). Infra-red, Raman and n.m.r. spectra, Polymer 23(1982) 714-721.

[48] B.Riegel, S.Blittersdorf, W.Kiefer, S.Hofacker, M.Müller, G.Schottner, Kinetic investigations of hydrolysis and condensation of theglycidoxypropyltrimethoxysilaner/aminopropyltriethoxy-silanesystem by means of FT-Raman spectroscopy I, J. Non-Cryst. Solids 226(1998) 76-84.

[49] P.T.K.Shih, J.L. Koenig, Raman studies of the hydrolysis of silanecoupling agents, Mater. Sci. Eng. 20 (1975) 137-143.

[50] H. Ishida, C.-H. Chiang, J.L. Koenig, The structure of aminofunctionalsilane coupling agents: 1. $\gamma$-aminopropyltriethoxysilane and its analogues, Polymer 23 (1982) 251-257.

[51] T. Nguyen, E. Byrd, D. Alshed, J. Chin, J. Martin, Relationship between interfacial water layer and adhesion loss of glass fiber-epoxy systems: A quantitative study, J. Adhesion 83 (2007) 587-610.

[52] M.M. Qayyum, J.R. White, Effect of stabilizers on residual stresses in weathered polyethylene, Polym.Degrad.Stab.39 (1993) 199-205.

[53] C.A. Klein, How accurate are Stoney's equation and recent modifications, J. Appl. Phys. 88 (2000) 5487-5489. 
Table 1.Raman band assignment for PET [28-30].

\begin{tabular}{llc}
\hline Band $\left(\mathrm{cm}^{-1}\right)$ & Assignment & Intensity \\
\hline 1726 & C=O stretch & vs \\
1614 & Ring C=C stretch & vs \\
1460 & Glycol C-H deformation & w \\
1416 & Ring C-C stretch & w \\
1373 & Glycol CH ${ }_{2}$ wagging & vw \\
1288 & Mixed mode of ring-carbonyl stretch, O-C stretch, and ring & \\
& CH in-plane bend & s \\
1184 & Ring CH in-plane bend & w \\
1115 & Mixed mode of ring CH in-plane bend,and glycol C-O stretch & m \\
1094 & Mixed mode of ring CH in-plane bend, glycol C-O stretch, & m \\
& COC and CCO bending, and C-C stretch & \\
998 & Mixed mode of glycol C-C stretch, O-CH ${ }_{2}$ stretch, andring & w \\
& torsion & w \\
893 & Glycol CH ${ }_{2}$ rocking & s \\
858 & Ring C-C breathing & w \\
795 & Ring CH out-of-plane & w \\
703 & Ring C-C-C out-of-plane bend & m \\
632 & Ring C-C-C in-plane bend & m \\
279 & Mixed mode of ring C-C-C in-plane, and ring C-C & \\
& out-of-plane &
\end{tabular}


Table 2.Raman band assignment for EVA [37-40].

\begin{tabular}{llc}
\hline Band $\left(\mathrm{cm}^{-1}\right)$ & Assignment & Intensity \\
\hline 2930 & Ethylene and acetate $\mathrm{CH}_{2}$ asymmetric stretch & $\mathrm{s}$ \\
2881 & Ethylene and acetate $\mathrm{CH}_{2}$ and $\mathrm{CH}_{3}$ stretch & $\mathrm{vs}$ \\
2848 & Ethylene and acetate $\mathrm{CH}_{2}$ stretch & $\mathrm{vs}$ \\
2722 & Aliphatic $\mathrm{CH}$ stretch & $\mathrm{m}$ \\
1727,1740 & Acetate C=O stretch & $\mathrm{w}-\mathrm{m}$ \\
1461 & Ethylene $\mathrm{CH}_{2}$ rockingdue to all-trans- $\left(\mathrm{CH}_{2}\right)_{\mathrm{n}^{-}}$ & $\mathrm{vs}$ \\
1440 & Ethylene and acetate $\mathrm{CH}_{2}$ bend & $\mathrm{vs}$ \\
1416 & Ethylene and acetate $\mathrm{CH}_{2}$ bend & $\mathrm{s}$ \\
1369 & Ethylene and acetate $\mathrm{CH}_{2}$ wagging & $\mathrm{w}$ \\
1296 & Ethylene $\mathrm{CH}$ twistingdue to all-trans- $\left(\mathrm{CH}_{2}\right)_{\mathrm{n}^{-}}$ & $\mathrm{vs}$ \\
1170 & CH ${ }_{2}$ rocking & $\mathrm{m}$ \\
1128 & Ethylene C-C symmetric stretchdue to all-trans- $\left(\mathrm{CH}_{2}\right)_{\mathrm{n}^{-}}$ & $\mathrm{vs}$ \\
1082 & Ethylene C-C asymmetric stretchoftrans and gauche & $\mathrm{s}$ \\
1062 & Ethylene C-C asymmetricstretchdue to all-trans- $\left(\mathrm{CH}_{2}\right)_{\mathrm{n}^{-}}$ & $\mathrm{vs}$ \\
1003 & Vinyl C-C of $>\mathrm{CH}-\mathrm{CH}_{2}$ stretch & $\mathrm{vw}$ \\
631 & Acetate O-C=O deformation & $\mathrm{w}$ \\
\hline
\end{tabular}




\section{Figure captions}

Figure 1.LSCM image of the cross-section of fresh PPE backsheet with various polymer layers and their corresponding thicknesses.

Figure 2.Representative raw Raman spectra (stacked)foreach layer of fresh PPE backsheet: (a) PET outer and PET core layers, (b) PET/PET and PET/EVA adhesive layers, and (c) three EVA layers.

Figure 3.The depth-dependent Raman spectra of PET outer layer after $1600 \mathrm{~h}$ aging in $\mathrm{UV} / 85^{\circ} \mathrm{C}$ at $5 \% \mathrm{RH}$ : (a) raw Raman spectra with Raman signals reside on baseline of fluorescence emission. The inset of bright field photomicrograph shows the corresponding measurement locations on the cross-section (epoxy is the molding compound), (b) fluorescence emission-subtracted Raman spectra (stacked) corresponding to the spectra in (a). The marked band $(*)$ is the $\mathrm{C}=\mathrm{O}$ of PET.

Figure 4.PET outer layer Raman images based on the fluorescence emission intensity at $1660 \mathrm{~cm}^{-1}$ after $1600 \mathrm{~h}$ aging in $\mathrm{UV} / 85{ }^{\circ} \mathrm{C}$ at $5 \% \mathrm{RH}(\mathrm{a})$, and at $60 \% \mathrm{RH}$ (c). Figures 4(b) and 4(d) are corresponding Raman imagesbased on the $\mathrm{C}=\mathrm{O}$ band intensity (fluorescence emission-subtracted)with 5\% $\mathrm{RH}$ and $60 \% \mathrm{RH}$ aging, respectively. All images are normalized to the same intensity from 0 to 1 , representing minimum to maximum intensity, with the UV exposed surface on the right side. Figures 4(e) and 4(f) are the intensity line profiles of the fluorescence emission intensity at $1660 \mathrm{~cm}^{-1}$ and $\mathrm{C}=\mathrm{O}$ Raman band intensity at $1727 \mathrm{~cm}^{-1}$, showing quantitative changes of these bands across the thickness of the PET outer later.Note that the gray region in Figure 4(f) represents one 
standard deviation for the fresh specimen.

Figure 5.The depth-dependent evolution of Raman spectra of PET outer layer after 1600 $\mathrm{h}$ aging in $\mathrm{UV} / 85^{\circ} \mathrm{C}$ at $5 \% \mathrm{RH}(\mathrm{a})$, and at $60 \% \mathrm{RH}(\mathrm{b})$. Two (2) $\mu \mathrm{m}, 4 \mu \mathrm{m} . .24 \mu \mathrm{m}$ are the depth from the UV exposed surface. All spectra here are fluorescence emission-subtracted. Figure 5(c) shows the intensity ratio between the bands at $1094 \mathrm{~cm}^{-1}$ and $1115 \mathrm{~cm}^{-1}$ as a function of depth.

Figure 6.PET core layer Raman images based on the $\mathrm{C}=\mathrm{O}$ band intensity(fluorescence emission-subtracted) before aging (a), and after $1600 \mathrm{~h}$ aging in UV/85 ${ }^{\circ} \mathrm{C}$ at $5 \% \mathrm{RH}(\mathrm{b})$, and at $60 \%$ RH (c). Figure 6(d) is the corresponding Raman image based onfluorescence emission intensity at $1660 \mathrm{~cm}^{-1}$ at $60 \% \mathrm{RH}$ aging. All images are normalized to the same intensity from 0 to 1 , representing minimum to maximum intensity, with PET outer layer on the right side.

Figure 7.The depth-dependent evolution of raw Raman spectra of PET core layer after $1600 \mathrm{~h}$ aging in $\mathrm{UV} / 85{ }^{\circ} \mathrm{C}$ at $5 \% \mathrm{RH}(\mathrm{a})$, and at $60 \% \mathrm{RH}(\mathrm{b})$. The schematic insets show the corresponding measurement locations on the cross-section. Layer thicknesses in the insets are not drawn to scale.

Figure 8.AFM topographic images of two adhesive layers. Top row: PET/PET adhesive, bottom row: PET/EVA adhesive; before aging (a), (b); after $1600 \mathrm{~h}$ aging in $\mathrm{UV} / 85{ }^{\circ} \mathrm{C}$ at $5 \% \mathrm{RH}(\mathrm{c}),(\mathrm{d})$, and at $60 \% \mathrm{RH}(\mathrm{e}),(\mathrm{f})$. The size of each image is $25 \mu \mathrm{m} \times 25 \mu \mathrm{m}$. 
Figure 9. Fluorescence emission-subtracted Raman spectra (stacked) of PET/PET adhesive layers before aging, and after $1600 \mathrm{~h}$ aging in $\mathrm{UV} / 85^{\circ} \mathrm{C}$ at $5 \% \mathrm{RH}$ and at $60 \%$ RH.

Figure 10.EVA layers Raman images based on the aliphatic $\mathrm{CH}$ band intensity (fluorescence emission-subtracted) before aging (a), and after $1600 \mathrm{~h}$ aging in $\mathrm{UV} / 85^{\circ} \mathrm{C}$ at $5 \% \mathrm{RH}(\mathrm{b})$, and at $60 \% \mathrm{RH}(\mathrm{c})$. Figure 10(d) is the corresponding Raman image of the fluorescence emission intensity at $1660 \mathrm{~cm}^{-1}$ with $60 \% \mathrm{RH}$ aging. All images are normalized to the same intensity from 0 to 1 , representing minimum to maximum intensity. Figures 10(e) and 10(f) are Raman intensity line profiles based on the aliphatic $\mathrm{CH}$ band intensity and fluorescence emission intensity, respectively. The dashed lines represent the interfaces between layers.

Figure 11. LSCM images of the exposed surface of PET outer layer before aging (a), and after aging in $\mathrm{UV} / 85^{\circ} \mathrm{C}$ at $60 \% \mathrm{RH}$ for $1600 \mathrm{~h}$ (b), and for $3280 \mathrm{~h}$ (c); Figures $11(\mathrm{~d})$ and 11 (e) are after aging in $\mathrm{UV} / 85^{\circ} \mathrm{C}$ at $5 \% \mathrm{RH}$ for $1600 \mathrm{~h}$ and $3280 \mathrm{~h}$, respectively. Figure 11(f) shows delamination between PET outer and PET core layers after $3280 \mathrm{~h}$ aging in $\mathrm{UV} / 85^{\circ} \mathrm{C}$ at $60 \% \mathrm{RH}$. The scale of the ruler is in millimeter. Note that the actual color is not reflected in the photograph. 


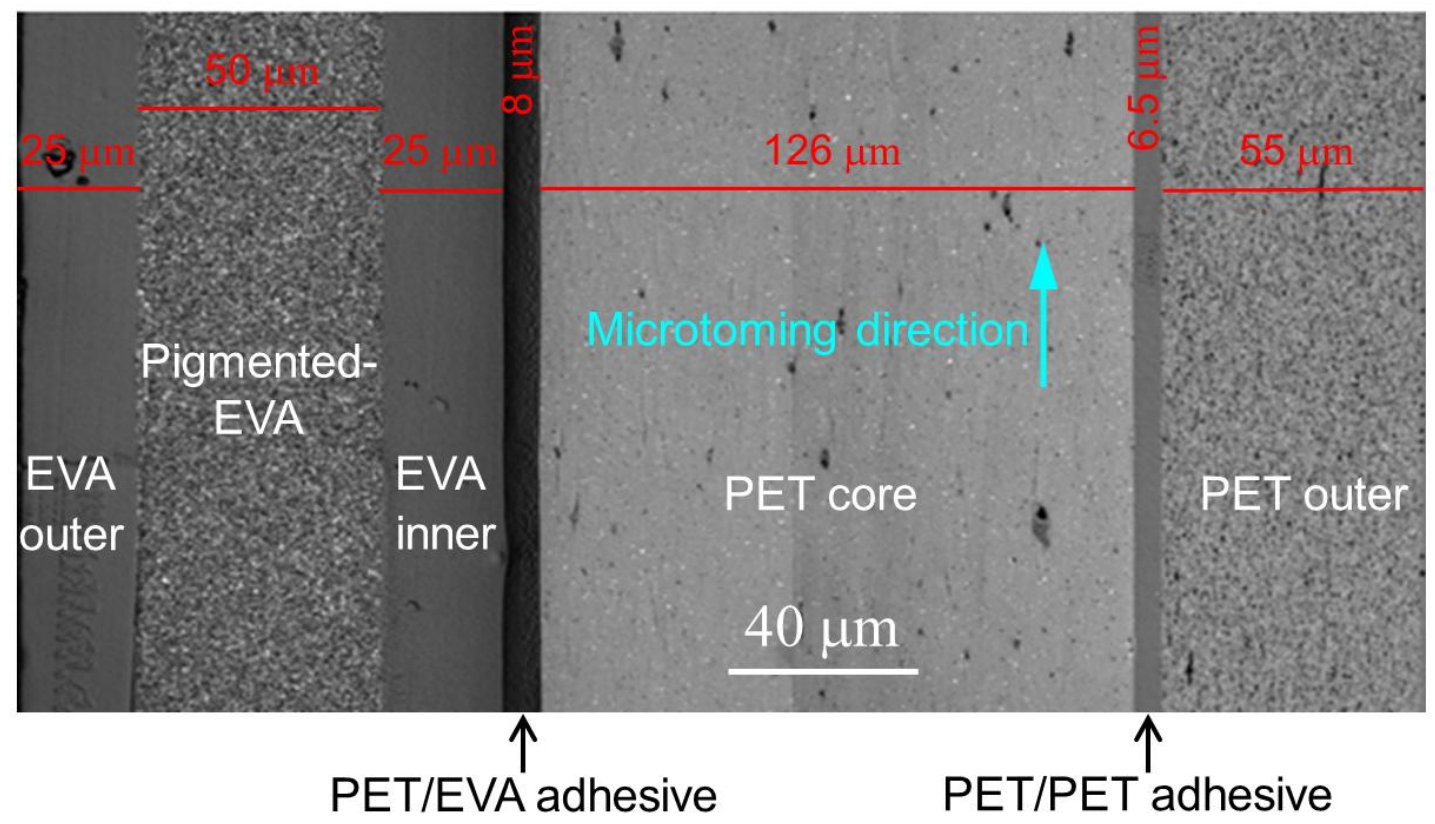

Fig. 1 

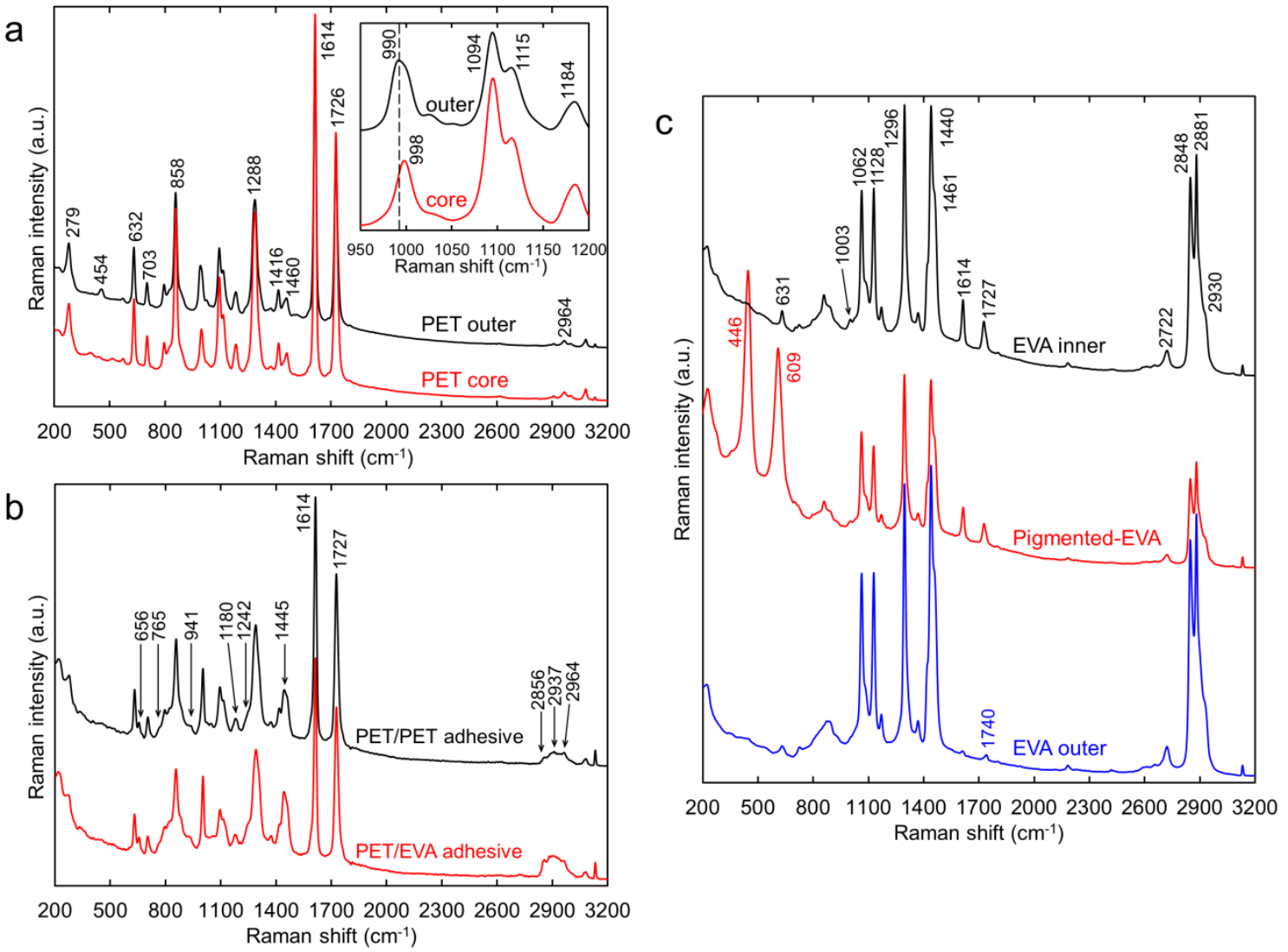

Fig. 2 

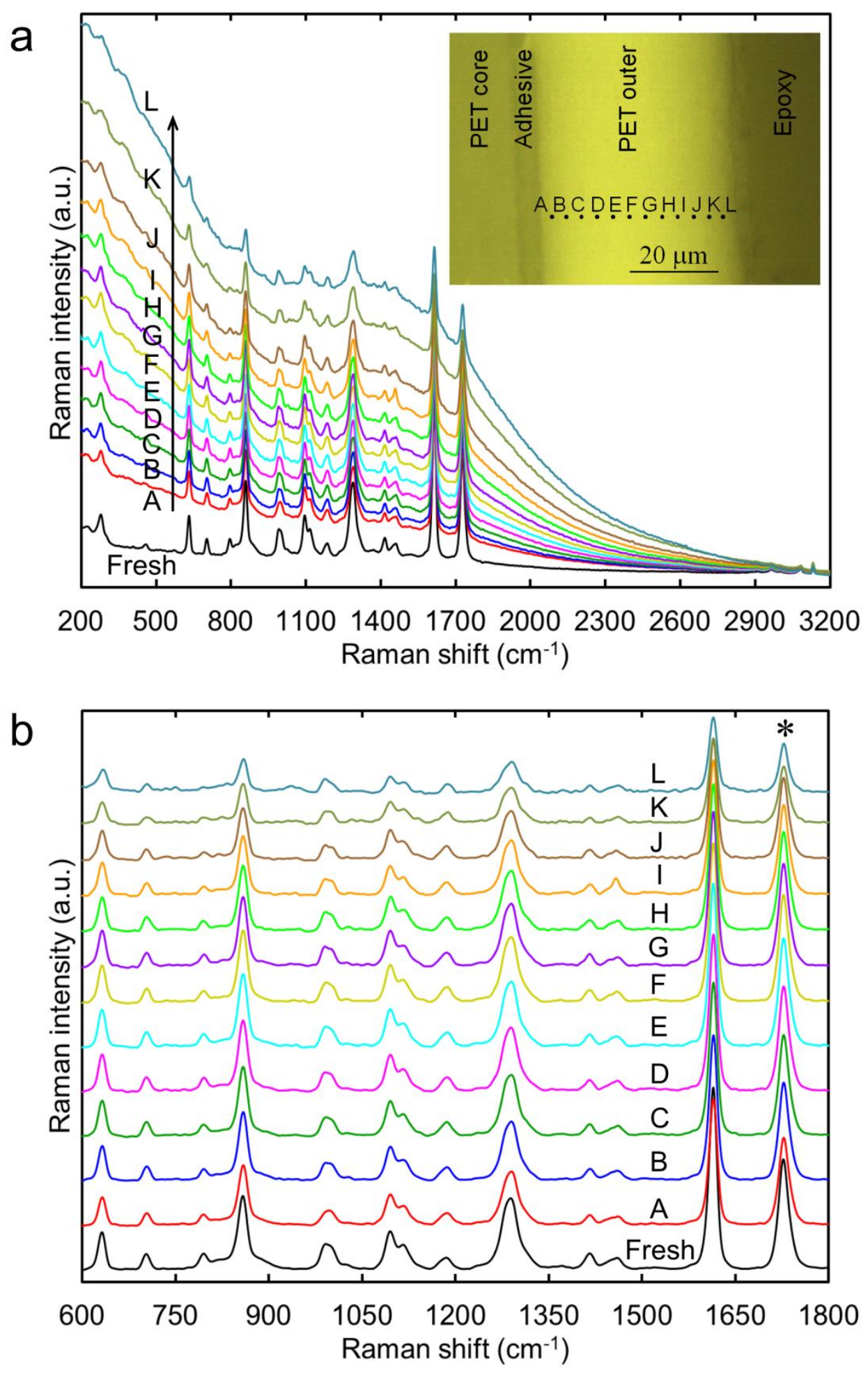

Fig. 3 

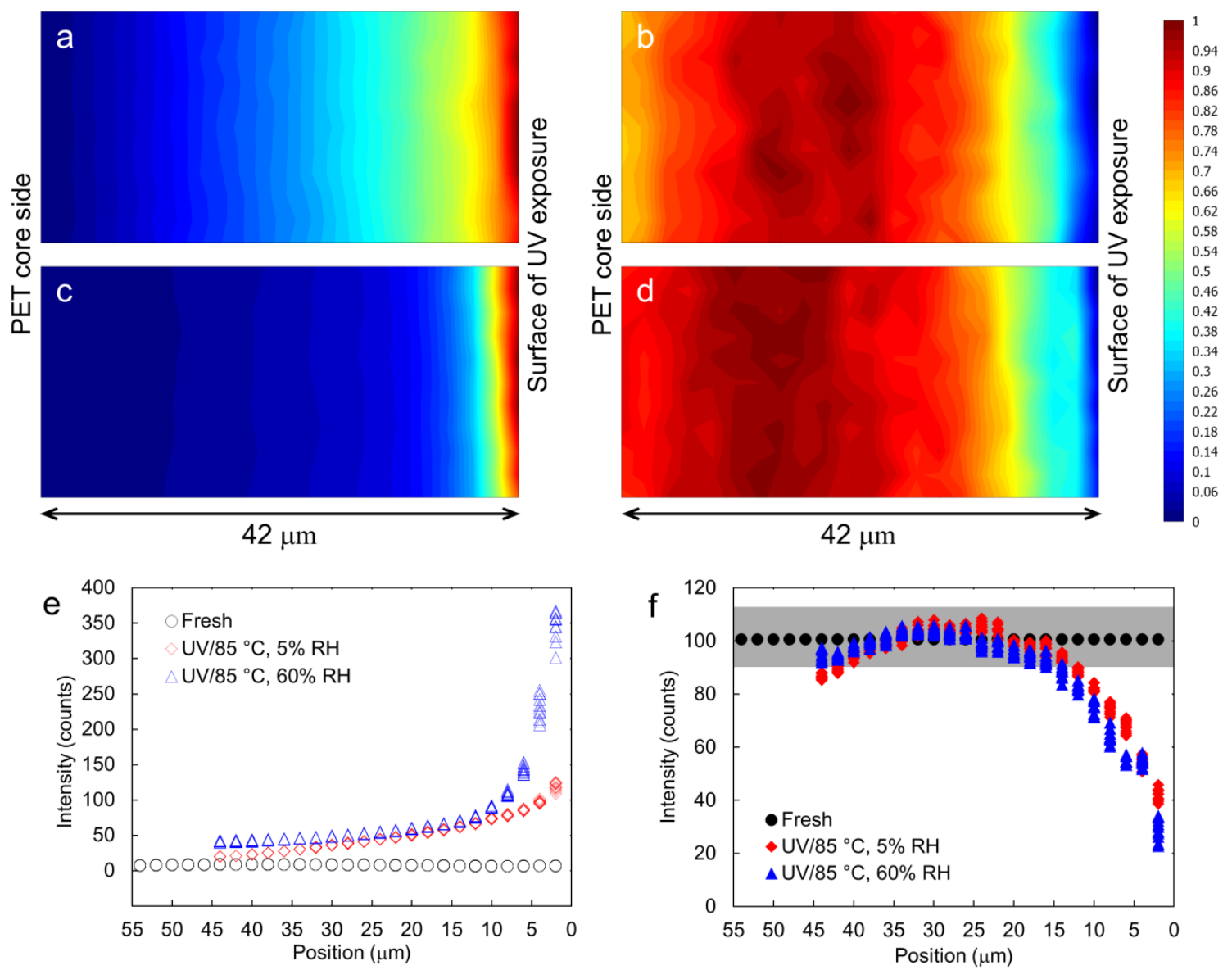

Fig. 4 

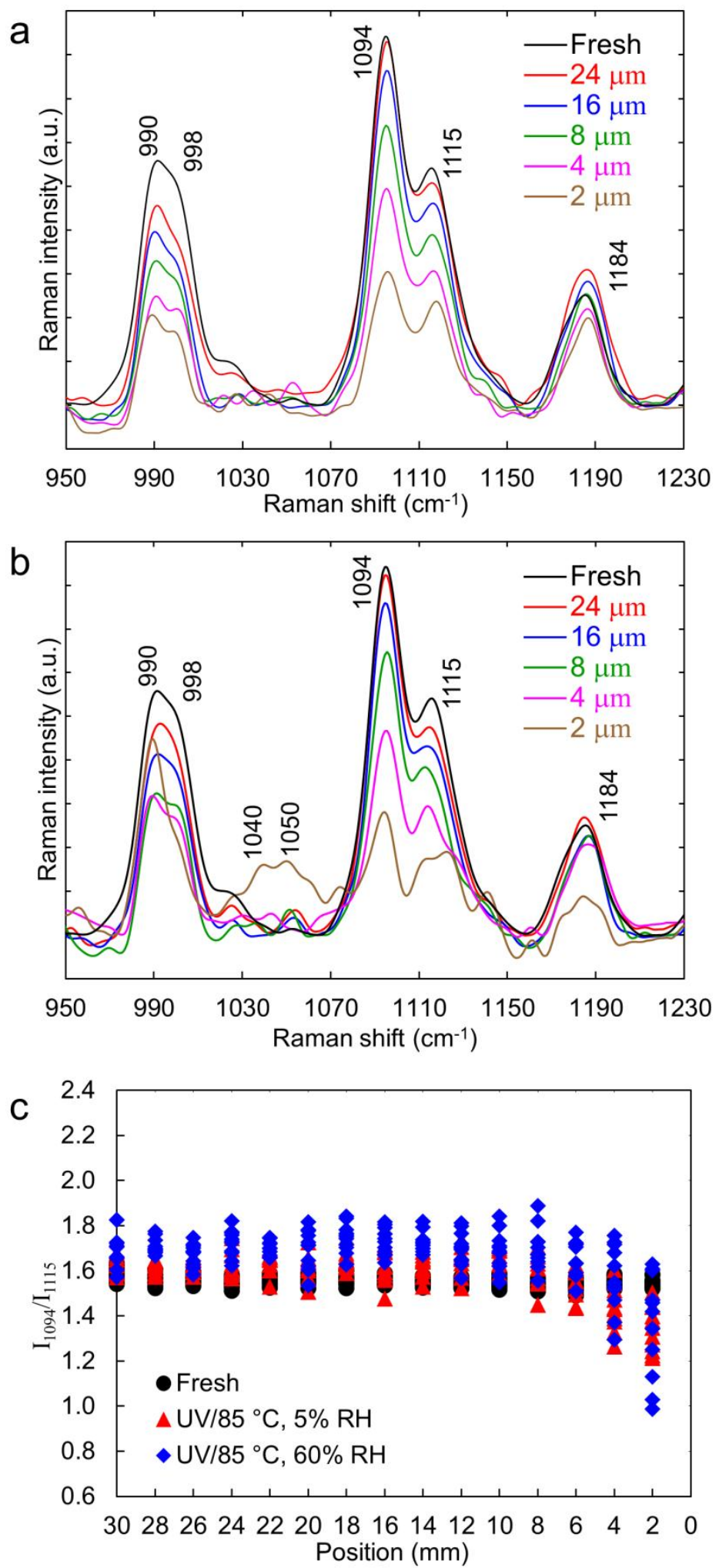

Fig. 5 


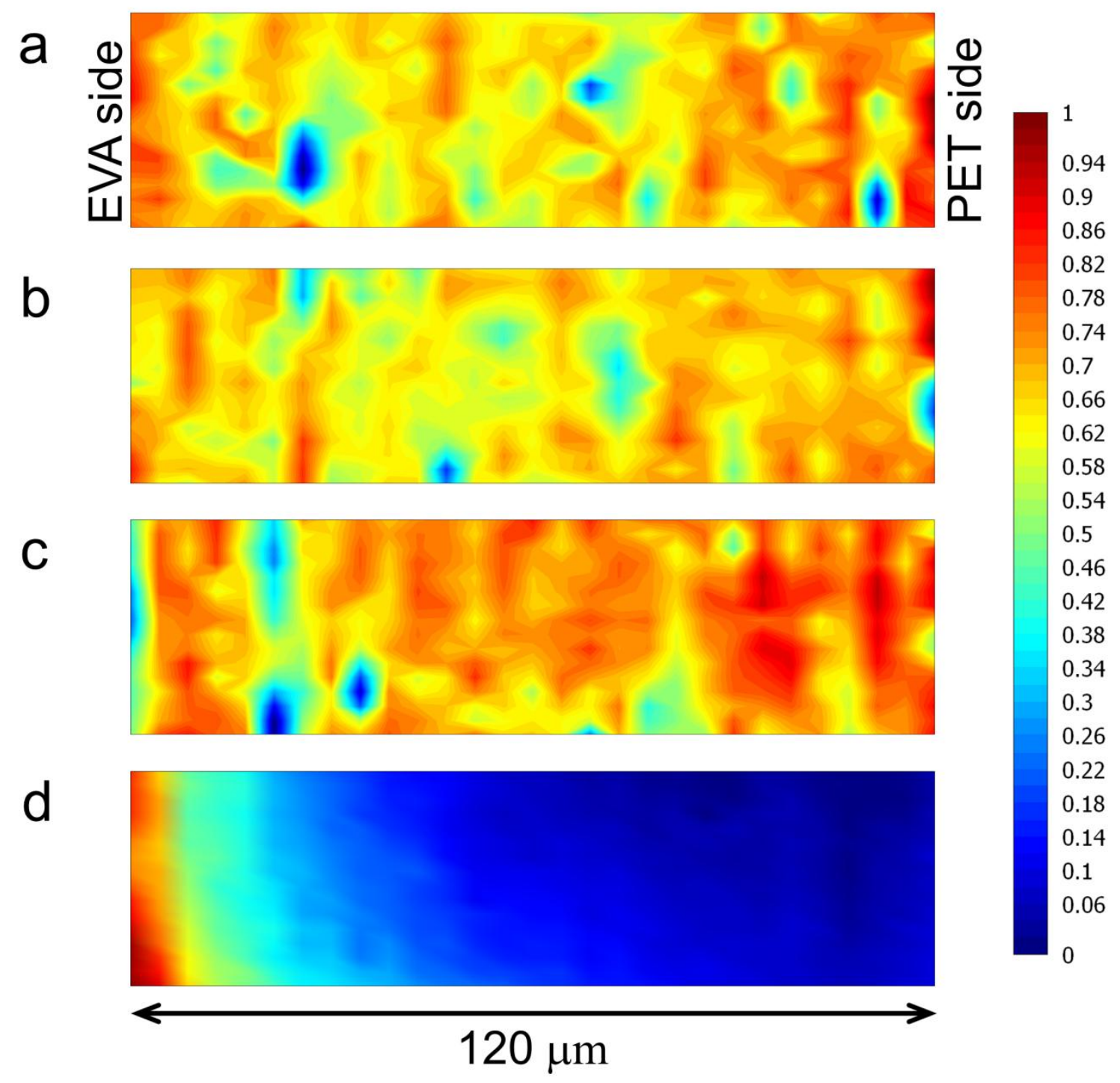

Fig. 6 

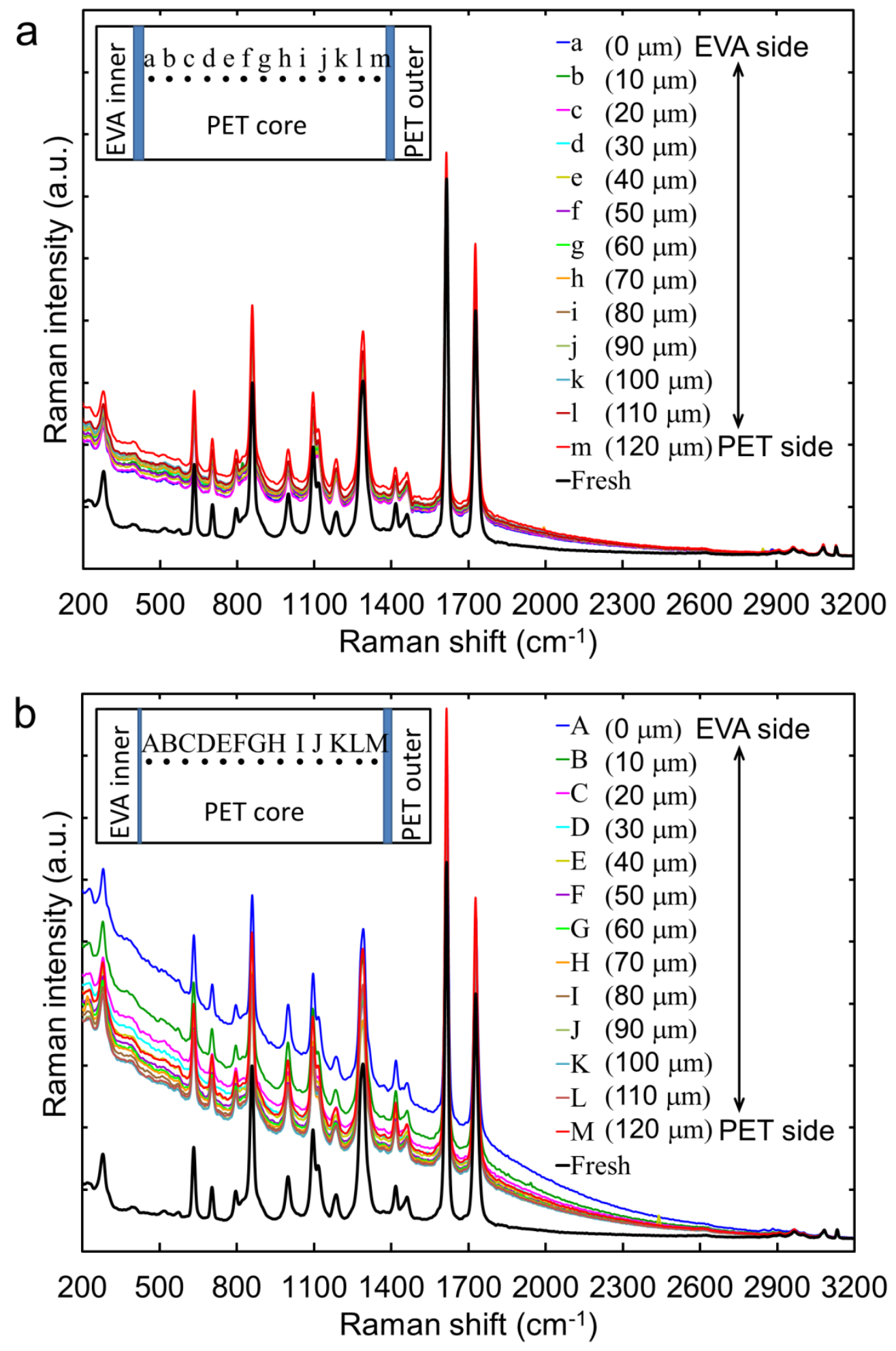

Fig. 7 

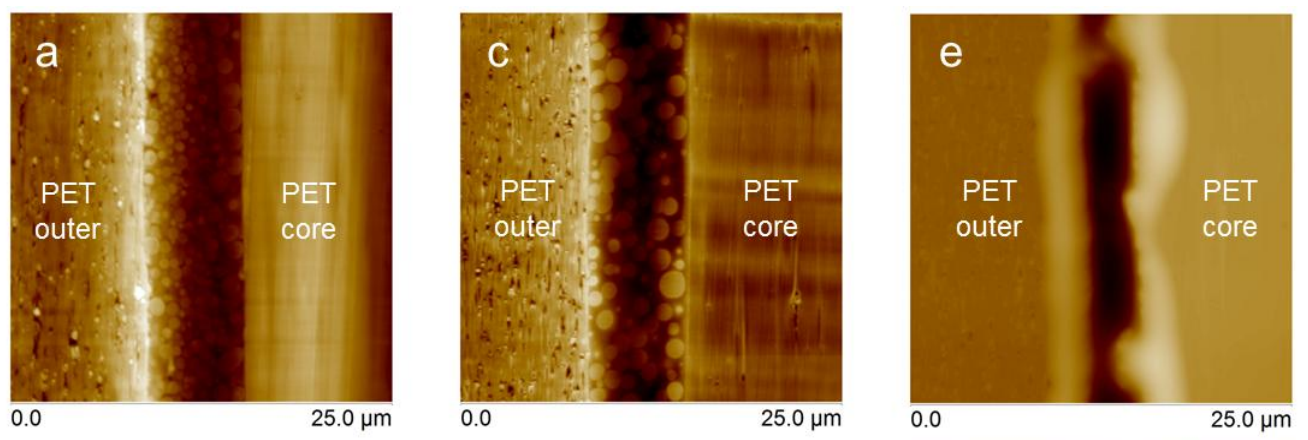

High
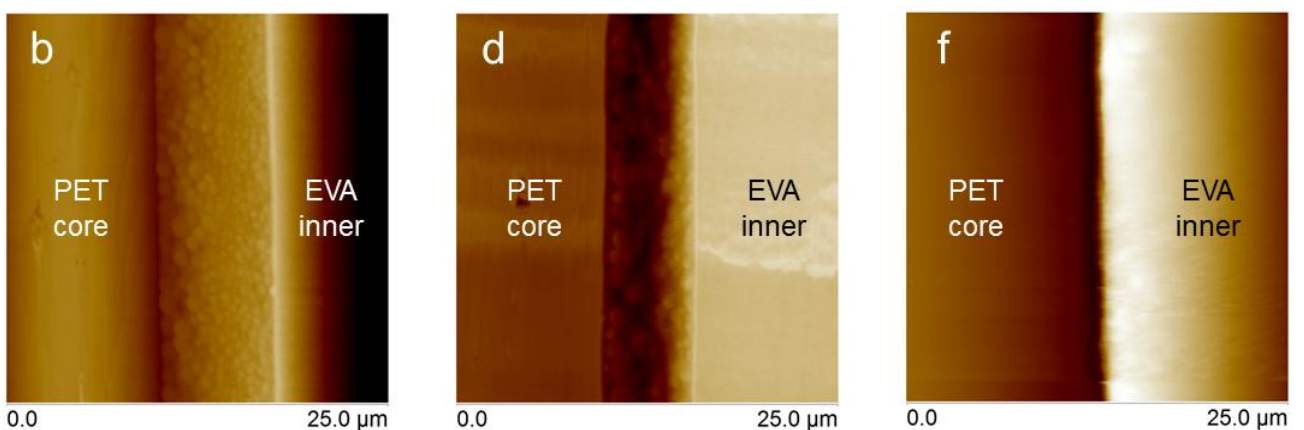

Fig. 8 


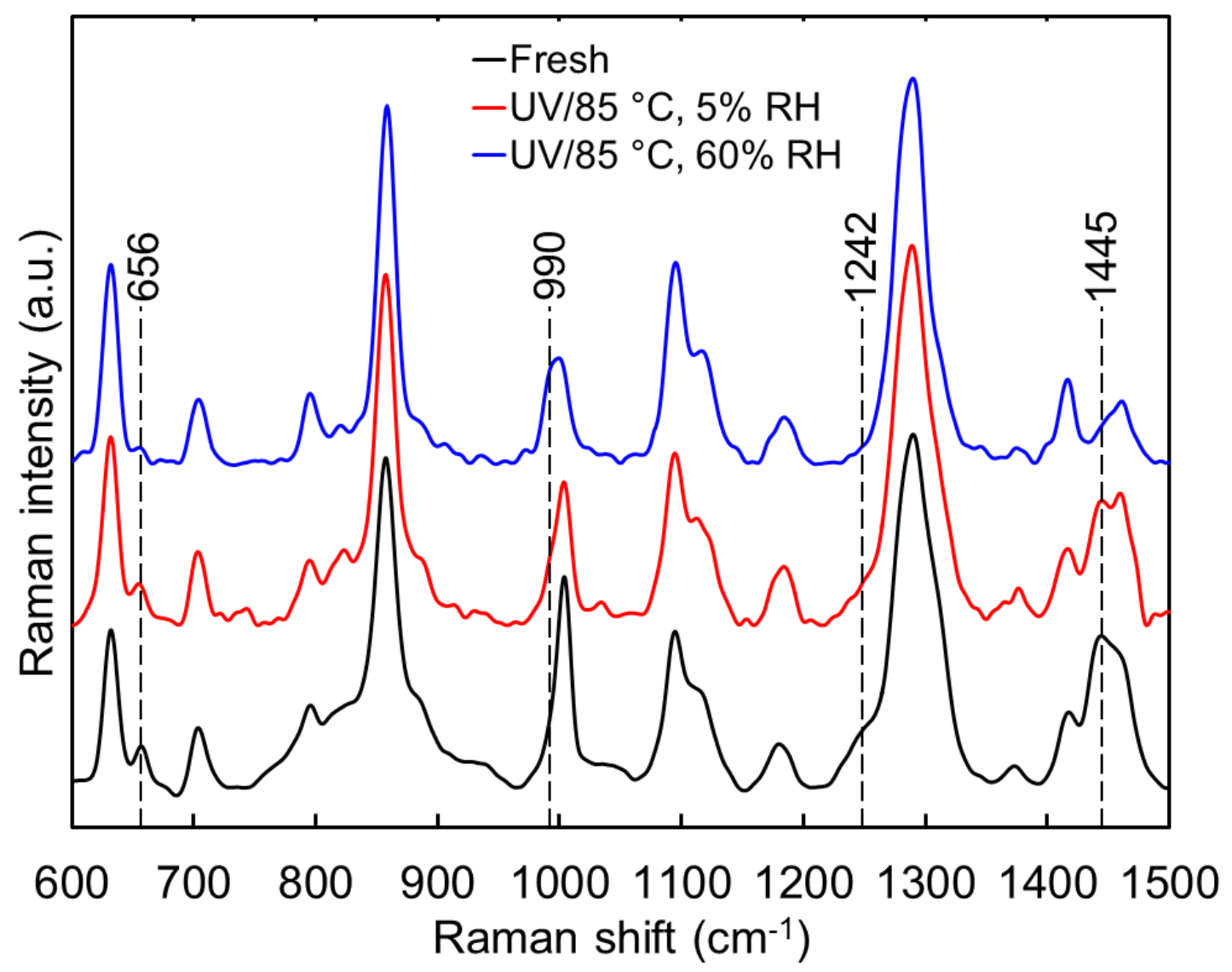

Fig. 9 

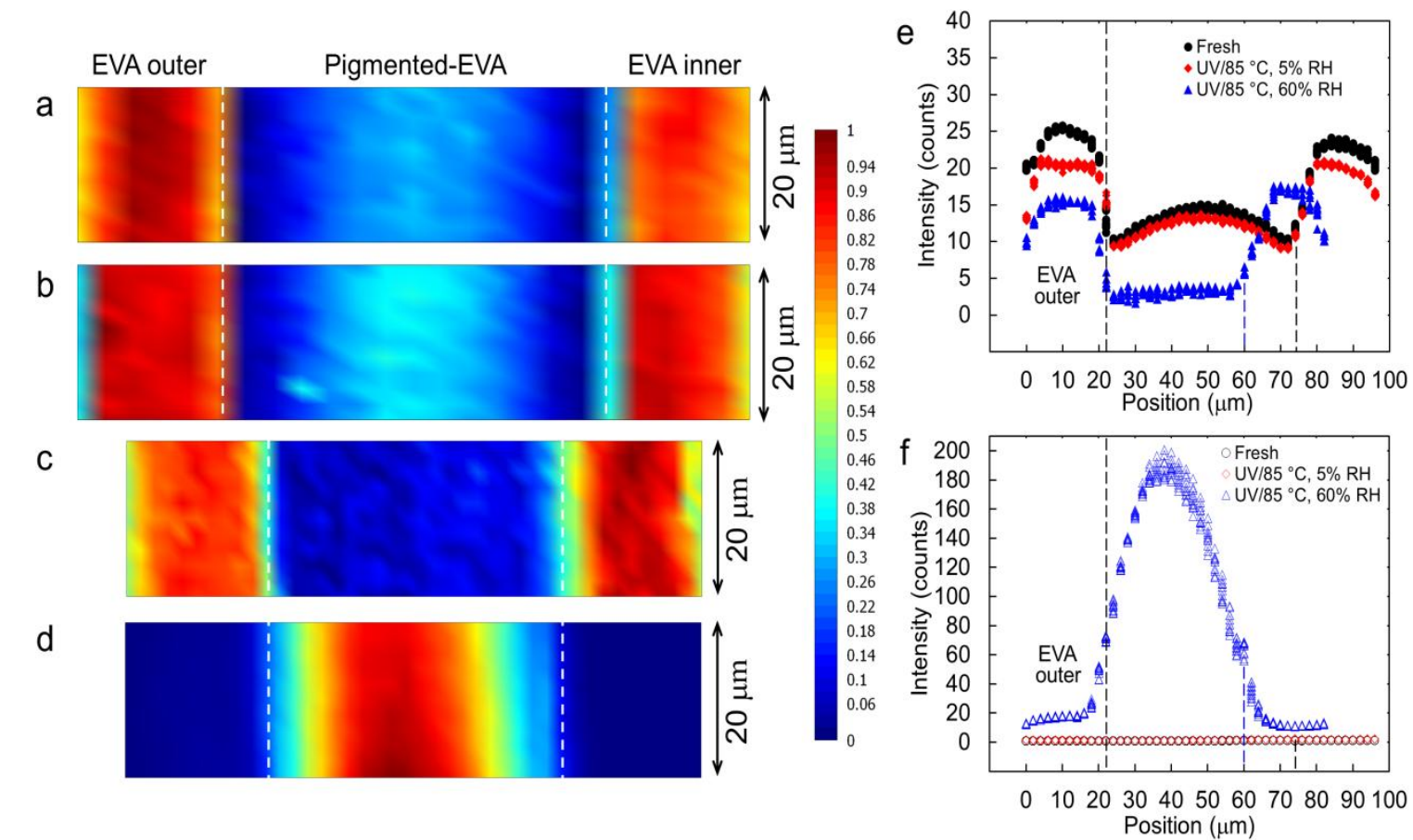

Fig. 10 

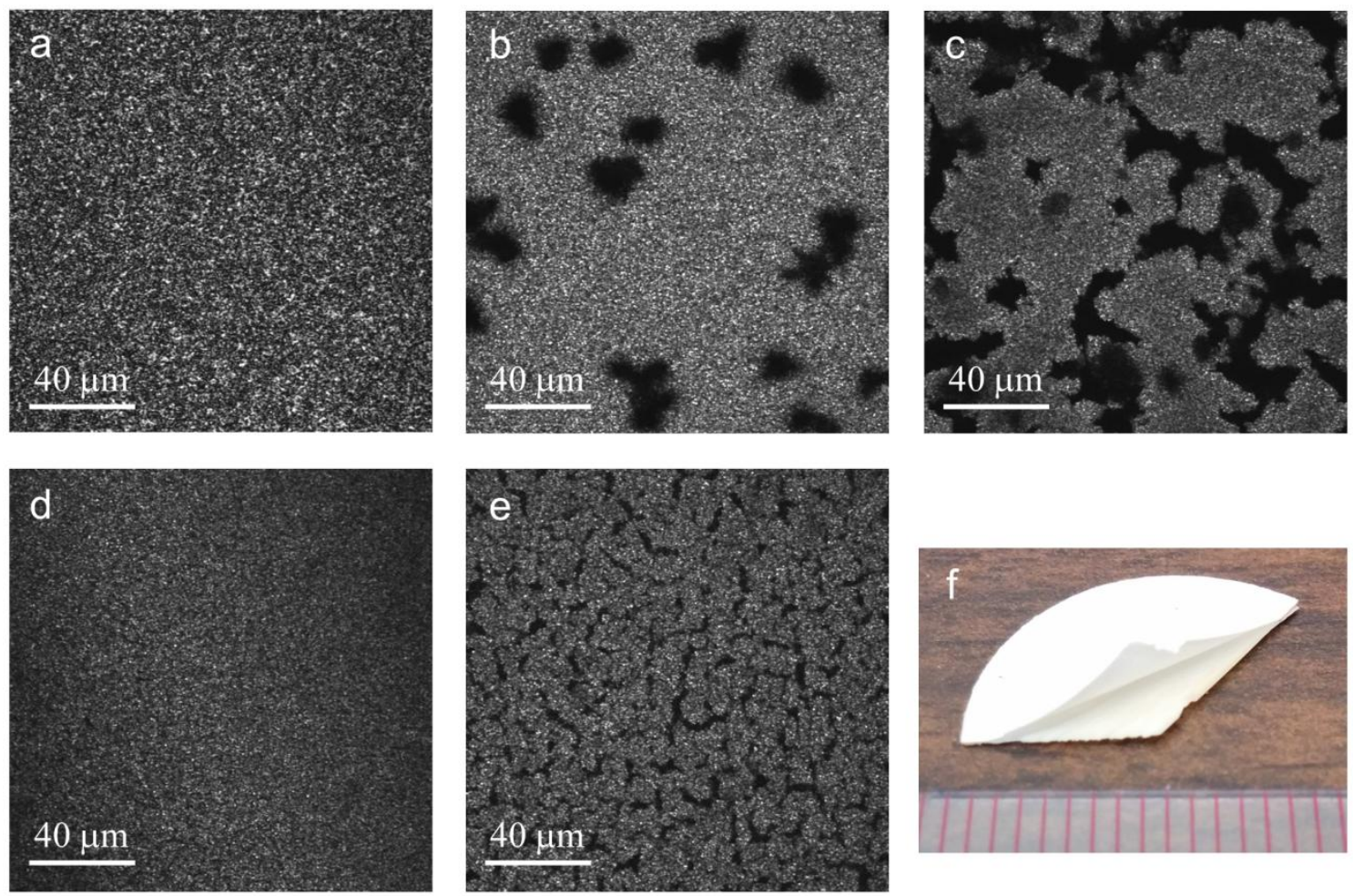

Fig. 11 


\section{Degradation profiles by Raman imaging:}

\section{$5 \% \mathrm{RH}$}

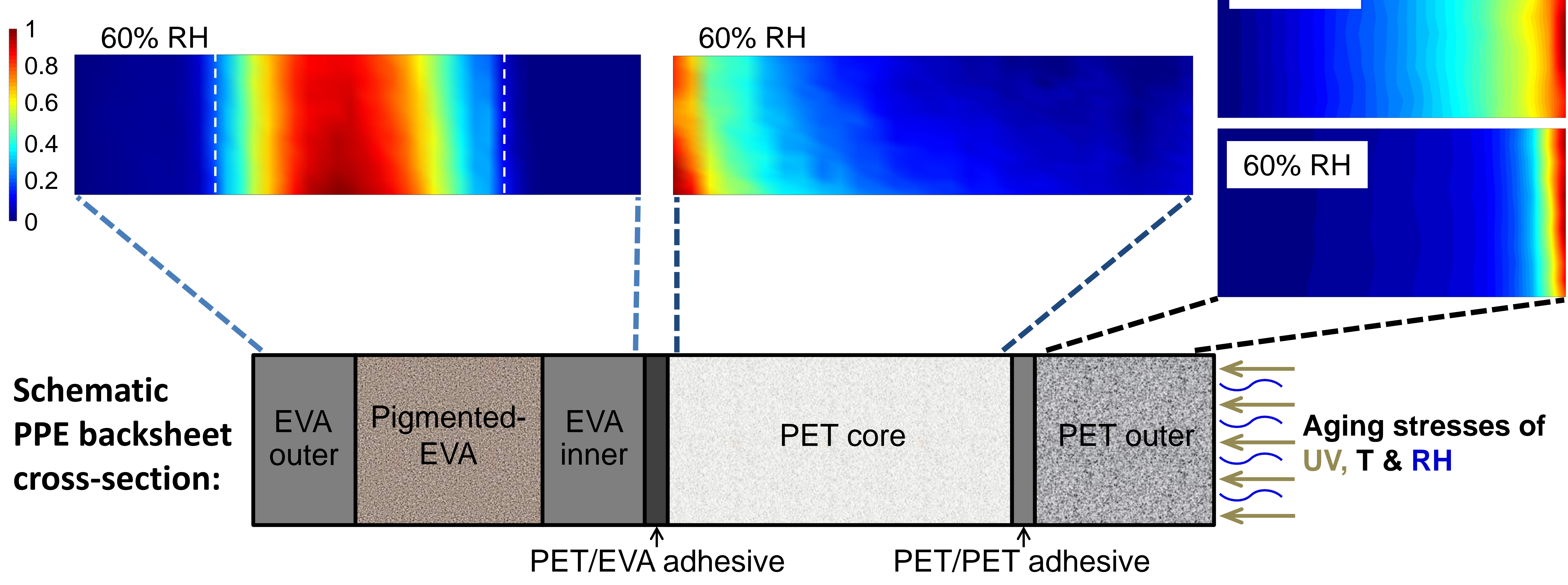

